\title{
Towards an understanding of barriers to condom use in rural Benin using the Health Belief Model: A cross sectional survey Sennen H Hounton*1,2, Hélène Carabin ${ }^{2}$ and Neil J Henderson ${ }^{3}$
}

Address: ${ }^{1}$ Department of HIV/AIDS and Reproductive Health, Centre MURAZ, Bobo-Dioulasso, Burkina Faso, ${ }^{2}$ Department of Biostatistics and Epidemiology, College of Public Health, University of Oklahoma, Oklahoma City, Oklahoma, USA and ${ }^{3}$ Department of Health Promotion Sciences, College of Public Health, University of Oklahoma, Oklahoma City, Oklahoma, USA

Email: Sennen H Hounton* - hounton_sennen@yahoo.fr; Hélène Carabin - helene-carabin@ouhsc.edu; Neil J Henderson - neilhenderson@ouhsc.edu

* Corresponding author

Published: 21 January 2005

BMC Public Health 2005, 5:8 doi:10.1 186/I 47/-2458-5-8

This article is available from: http://www.biomedcentral.com/I47I-2458/5/8

(c) 2005 Hounton et al; licensee BioMed Central Ltd.

This is an Open Access article distributed under the terms of the Creative Commons Attribution License (http://creativecommons.org/licenses/by/2.0), which permits unrestricted use, distribution, and reproduction in any medium, provided the original work is properly cited.
Received: 15 July 2004
Accepted: 21 January 2005

\begin{abstract}
Background: HIVIAIDS is the most dramatic epidemic of the century that has claimed over two decade more than 3 million deaths. Sub Saharan Africa is heavily affected and accounts for nearly $70 \%$ of all cases. Despite awareness campaigns, prevention measures and more recently promotion of anti viral regimens, the prevalence of cases and deaths is still rising and the prevalence of systematic condom use remains low, especially in rural areas. This study identifies barriers to condom use based on the Health Belief Model (HBM) in Benin, West Africa.
\end{abstract}

Methods: The study was a cross-sectional survey conducted from June to July 2002. Two hundred fifty one (25I) individuals were interviewed using a structured questionnaire adapted from a standardized WHO/GAP questionnaire. A logistic regression was used to identify factors associated with condom use.

Results: In spite of satisfactory knowledge on HIVIAIDS transmission, participants are still at high risk of contracting the infection. Sixty three (63) percents of the interviewees reported being able to recognize infected people, and condom use during the last occasional intercourse was declared by only $36.8 \%$ of males and $47.5 \%$ of females. Based on the HBM, failure to use condom was related to its perceived lack of efficacy $[O R=9.76(3.7 \mathrm{I}-30.0)]$ and perceived quality $[O R=3.6 \mathrm{I}(\mathrm{I} .3 \mathrm{I}-$ 9.91)].

Conclusions: This study identifies perceived efficacy (incomplete protective effect) and perceived utilization-related problem (any reported problem using condoms) as the main barriers to condom use. Hence, preventions strategies based on increasing perceived risk, perceived severity or adequate knowledge about HIVIAIDS may not be sufficient to induce condom use. These data will be useful in designing and improving HIVIAIDS prevention outreach programs in Sub Saharan Africa.

\section{Background}

One of the current challenging tasks faced by health professionals and scientists worldwide is the prevention and control of HIV/AIDS. This disease claims yearly a huge toll of deaths, productivity and economic losses, especially in sub-Saharan Africa where the population is already 
weakened by poverty, malaria and tuberculosis [1,2]. Curtailing the HIV/AIDS pandemic requires a holistic approach [3]. In Benin, several programmes have been developed to target high-risk groups and to modify cultural risk factors for the transmission of the infection [47]. Nonetheless, the prevalence of HIV infection and the rate of other sexually transmissible Infections (STI), and the number of people living with HIV/AIDS (PLWHA) are still increasing [8,9]. In Benin (and in most of West African countries), limited accessibility to anti retroviral medication (ARV) has pushed public health authorities to focus on prevention measures. Nowadays, most of the efforts are being shifted towards access to ARV, care to PLWHA [10], and second generation surveillance. However, there is a scarcity of operational research designed to identify barriers and facilitators to behavioural change $[11,12]$. This study, which was conducted in rural Benin, identifies factors deterring condom use that could be targeted by HIV outreach programmes using the Health Belief Model (HBM) framework. The Health Belief Model postulates that an individual's actions are based on beliefs. It underlines main factors for decision making such as perceived vulnerability or susceptibility, perceived severity of the outcome or conditions, perceived efficacy or benefit of control measure and the perceived barriers to prevention. It has been extensively used in behavioural sciences to predict behaviours and to design behavioural prevention programs. [13-15]

\section{Methods}

\section{Study location and participants}

Benin is a West-African country with a population of 6.2 million people. The male/female sex ratio is $0.96,48.5 \%$ of the population is under age 15, the rate of literacy is nearly $30.0 \%$ and farming as the main occupation [2]. The study was conducted in Toffo, a county with a population of 80,000 inhabitants, located 50 miles north of Cotonou, the economic capital of Benin. Individuals aged 15 to 55 years old living in Toffo between June 10 and July 23, 2002 were invited to participate in the study. Health professionals, individuals less than 15 years old and school teachers were excluded from the study. Authorization to conduct the study was obtained from the Ministry of Health and the National STI/HIV/AIDS programme in Benin.

\section{Sample size, sampling and data collection}

The sample size was calculated based on results from the Benin 2001 Demographic and Health Survey [2]. Using the proportion of condom use reported in that survey $(14.6 \%)$ and to detect a difference of $10 \%$ with a power of $90 \%$ and an error of 5\%, a sample size of 245 people was needed [16]. A stratified random sample was applied using the 10 villages of Toffo as strata, and an average of 25 individuals per stratum was invited to participate after a brief presentation of the study, its aims and its potential applications. Participation was voluntary and participants could withdraw anytime during the interview. 270 individuals in the catchments area were invited and 251 accepted to participate in the study. Sixteen completed forms were removed from the analysis because of incomplete data on demographic characteristics and key responses related to the Health Belief Model. The final sample size was 235. Data were collected using a questionnaire adapted from the surveillance questionnaire developed by the Global AIDS Program of the World Health Organization (see survey items in Annexes). A pretest of the questionnaire was carried out on a convenient sample of 20 people of both genders living in Toffo and interviewers (3 social workers, one female and 2 males) were trained by SHH using simulated interviewees.

\section{Data analysis}

Data were stored in a file using Epi info 2000 [3] and then imported in SPSS 11.0 [17] and in SAS 8.1 [18]. The analysis included descriptive statistics, cross-tabulation and logistic regression. The following variables were included in the analysis: socio-demographic characteristics, perceived vulnerability (participant feeling at risk or not), perceived severity of the disease (AIDS perceived as deadly or not), perceived efficacy (condom effective to prevent infection or not), perceived barrier (any reported problem with use of condoms) and condom use during the last occasional sexual intercourse

\section{Results}

\section{Socio-demographic characteristic}

The age distribution of the study population was similar to that of the Benin population [2]. Table 1 shows that there were 1.9 times more males than females sampled and the former were older (difference between mean age $=3.2$ years with $95 \% \mathrm{CI}=1.8-4.5)$. A proportion of $69 \%$ of the participants declared being married (monogamous or polygamous) and $28 \%$ single. Farming was the most common reported occupation (37.4\%) followed by laborers and small business. Sixty-six percent of males compared to $30 \%$ of females declared not having had any school education. The most common reported religion was Christianity (52\%) albeit polytheism being a social fact in Benin. Nearly two-thirds of the participants (63\%) declared "Fon" as their ethnic group. There was no significant difference in socio-demographic variables by gender.

\section{Knowledge}

Table 2 presents a summary of the knowledge of the participants on HIV/AIDS and crude odds ratio estimates comparing males to females. There was a high awareness of AIDS $(99,9 \%)$, and its perceived risk (97\% of participants considered AIDS as a deadly disease) among 
Table I: Socio-demographic characteristics of 235 participants in a HIVIAIDS interview, Toffo county, Benin (June-July 2002)

\begin{tabular}{|c|c|c|c|}
\hline Characteristics & Males N (\%) & Females N (\%) & Total N (\%) \\
\hline All participants & $155(66.0)$ & $80(34.0)$ & 235 \\
\hline \multicolumn{4}{|l|}{ Age groups } \\
\hline $15-24$ & $56(36.1)$ & $37(46.3)$ & $93(39.6)$ \\
\hline $25-34$ & $52(33.5)$ & $29(36.3)$ & $81(34.4)$ \\
\hline $35-44$ & $30(19.4)$ & $5(6.3)$ & 35 (14.9) \\
\hline $45+$ & $17(11.0)$ & $9(11.3)$ & $26(11.1)$ \\
\hline \multicolumn{4}{|l|}{ Marital status } \\
\hline Married, monogamous & $87(56.1)$ & $27(33.8)$ & I I 4 (48.5) \\
\hline Married, polygamous & $23(14.8)$ & $24(30.0)$ & $47(20.0)$ \\
\hline Single & $44(28.4)$ & $21(26.3)$ & $65(27.7)$ \\
\hline Widow, Separated & I $(0.7)$ & $8(0.9)$ & 09 (07.3) \\
\hline \multicolumn{4}{|l|}{ Occupation } \\
\hline Farming & $81(52.3)$ & $7(8.8)$ & $88(37.4)$ \\
\hline Working class & $48(31.0)$ & $7(8.8)$ & $55(23.4)$ \\
\hline Small business & $10(6.5)$ & $33(4 I .3)$ & $43(18.3)$ \\
\hline Housewife & NA & $21(26.3)$ & $21(08.9)$ \\
\hline High school student & $4(1.7)$ & II (4.7) & $15(06.4)$ \\
\hline Other & $12(7.7)$ & $1(1.3)$ & $13(05.6)$ \\
\hline \multicolumn{4}{|l|}{ Educational level } \\
\hline None & $47(30.3)$ & $48(60.0)$ & $95(40.4)$ \\
\hline Some & $108(69.7)$ & $32(40.0)$ & $140(59.6)$ \\
\hline \multicolumn{4}{|l|}{ Ethnicity } \\
\hline Fon & $104(67.1)$ & $46(57.5)$ & $149(65.1)$ \\
\hline Aizo & $26(16.8)$ & $24(30.0)$ & $49(21.4)$ \\
\hline Other & $25(16.1)$ & $10(12.5)$ & 37 (13.5) \\
\hline \multicolumn{4}{|l|}{ Religion } \\
\hline Christian & $42(52.5)$ & $80(51.6)$ & $122(51.9)$ \\
\hline Muslim & $3(3.8)$ & $2(1.3)$ & $5(2.1)$ \\
\hline Traditional & $21(26.3)$ & $54(34.8)$ & 75 (31.9) \\
\hline Other & $14(17.5)$ & $19(12.3)$ & $33(14.0)$ \\
\hline
\end{tabular}

participants. Females were more aware than males of the modes of transmission of HIV infection ( $87 \%$ of females versus 50\% reported knowing at least 2 modes of transmission). There was a difference in preventive measures for HIV/AIDS by gender: Females reported mainly fidelity and abstinence whilst males primarily reported condom use. In addition, $84 \%$ of females whereas $52 \%$ of males reported being able to identify an HIV-infected person. This indicates the need for improving knowledge of the disease in general for both genders. Education level and religion did not have a meaningful effect on knowledge across age groups.

\section{Behavioural risk factors}

The overall condom use in this population was low (34\%). Table 3 describes the distribution of frequency of not ever using condom, last occasional intercourse without condom use and median number of sexual partners during the past 12 months, according to age, gender, education and marital status. Single participants with some education declared using condom more frequently. The proportion of subjects who declared using condom decreased with age and with males being marginally more likely to declare using it than females. We did not find any significant difference about reports on the use of condom during the last occasional intercourse by age groups, gender, educational or marital status. The small number of individuals declaring condom use during the last occasional intercourse maybe the reason why no significant associations were found.

However, it is interesting to note that whilst females declared ever using condom less often than males, they declared having used the condom during the last occasional intercourse more often. In particular, even though $73 \%$ of females declared never using the condom, $47 \%$ declared having used it during the last occasional intercourse. None of these differences were significant but they clearly indicated contradictory tendencies and answers to the questionnaire. It may be that among females who ever used condom, they use it more frequently than males. Finally, the median number of sexual partners during the 
Table 2: Distribution of knowledge by gender of 235 participants in a HIVIAIDS interview, Toffo county, Benin (June-July 2002 ).

\begin{tabular}{|c|c|c|c|}
\hline Knowledge & Male & $\begin{array}{l}\mathrm{N}(\%) \\
\text { Female }\end{array}$ & $\begin{array}{r}\text { Difference* (\%) } \\
{[95 \% \mathrm{Cl}]}\end{array}$ \\
\hline \multicolumn{4}{|l|}{ Have you ever heard of HIVIAIDS? } \\
\hline Yes & $154(99.4)$ & $80(100)$ & $-0.6[-1.8 ; 6.2]$ \\
\hline \multicolumn{4}{|l|}{ What is your source of information? } \\
\hline Radio ( \pm other sources) & $146(94.2)$ & $58(72.5)$ & $21.7[11.3 ; 32.2]$ \\
\hline Health professionals (only) & $4(2.6)$ & $8(10.0)$ & $-7.4[-14.4 ;-0.4]$ \\
\hline Friends (only) & $5(3.2)$ & $14(17.5)$ & $-14.3[-23.1 ;-5.5]$ \\
\hline \multicolumn{4}{|l|}{ According to your knowledge, what is AIDS? } \\
\hline Deadly disease & $134(86.5)$ & $79(99.8)$ & $-13.3[-18.7 ;-7.8]$ \\
\hline Projected disease & $17(11.0)$ & $\mathrm{I}(1.2)$ & $9.8[4.3 ; 15.3]$ \\
\hline Don't know & $3(1.9)$ & $0(0.0)$ & $1.9[-2.5 ; 4.0]$ \\
\hline Other & $\mathrm{I}(0.6)$ & $0(0.0)$ & $0.6[-0.6 ; 1.8]$ \\
\hline \multicolumn{4}{|l|}{ Modes of transmission of HIV? } \\
\hline Knows at least two modes of transmission & $77(49.0)$ & $70(87.0)$ & $-38[-48.8 ;-27.2]$ \\
\hline Knows sexual transmission & $68(43.9)$ & $6(7.5)$ & $36.4[26.7 ; 46.1]$ \\
\hline Do not know any & $9(6.5)$ & $4(5.0)$ & $1.5[-4.6 ; 7.6]$ \\
\hline \multicolumn{4}{|l|}{ Prevention } \\
\hline \multicolumn{4}{|l|}{ What are the prevention methods of getting HIV? } \\
\hline Abstinence /fidelity & $13(8.4)$ & $44(55.0)$ & $-46.6[-58.3 ;-34.8]$ \\
\hline Serological test. & $0(0.0)$ & $8(10.0)$ & $-10[-16.6 ;-3.4]$ \\
\hline Condom & $13 \mid(84.5)$ & $20(25.0)$ & $59.5[48.4 ; 70.6]$ \\
\hline Don't know & $4(2.6)$ & $0(0.0)$ & $2.6[0.0 ; 5.1]$ \\
\hline Other & $7(4.5)$ & $8(10.0)$ & $-5.5[-12.8 ; 1.8]$ \\
\hline \multicolumn{4}{|l|}{ How can a HIV-infected person be identified? } \\
\hline Symptoms & $80(51.6)$ & $67(83.8)$ & $-32.2[-43.5 ;-21]$ \\
\hline Can not differentiate & $23(14.8)$ & $2(2.4)$ & $12.4[5.9 ; 19]$ \\
\hline Don't know & $49(31.6)$ & $11(13.8)$ & $17.8[7.3 ; 28.3]$ \\
\hline Other & $3(2.0)$ & $0(0.0)$ & $2[-0.2 ; 4.2]$ \\
\hline
\end{tabular}

Difference* $=$ Difference between males and females in the prevalence of knowledge with $95 \%$ confidence interval (using a binomial distribution)

last 12 months varied by gender ( 2 for males versus 1 for females), by education ( 2 for some versus 1 for none) and by marital status ( 2 for single versus 1 for other) but not by age groups.

\section{Determinants of condom use behavioural change}

Overall, there was a high perceived risk of contracting HIV infection among interviewees: 94\% considered themselves as vulnerable to HIV/AIDS. This proportion was higher in females compared to males. Similarly there was a high perceived severity of HIV/AIDS: 99\% of females compared to $87 \%$ of males perceived HIV/AIDS as a severe and deadly disease. Conversely, there was a relatively low perceived efficacy of condom as a protective measure: only $37 \%$ of the interviewees perceived condom as an effective mean in protecting from getting HIV infection. We identified several socio-cultural barriers to behavioural change namely reported problems using condom (88\% of the interviewees), the alleged capability to physically recognize an HIV infected person and the denial all together of the disease (only 19\% participants believe HIV/AIDS exists). Also, cultural practices such as polygamy (20\% of the study population), poverty, the belief that there is a cure for the disease (74\%) and religion ( $9 \%$ of non favorable reaction towards condom are among declared Christians) were all not favorable to HIV infection control.

\section{Logistic regression using the theoretical health belief model}

Table 4 describes the results of a logistic regression, fitted to assess the strength of association between perceived vulnerability (participant feeling at risk or not), perceived severity of the disease (AIDS perceived as deadly or not), perceived efficacy (condom effective to prevent infection or not), perceived barrier (problems with using condoms) and the lack of condom use. Perceiving condom as ineffective ( $\mathrm{OR}=9.8,95 \% \mathrm{CI}=3.2-30.0)$ and having reported problems with using the condom $(\mathrm{OR}=3.6,95 \% \mathrm{CI}=$ 1.3-9.9) were both associated with the lack of use of condom. However, perceiving oneself as vulnerable to HIV 
Table 3: Distribution of selected behavioural risk factors of 235 participants in a HIVIAIDS interview by age groups, gender, education level and marital status in Toffo county, Benin (June-July 2002)

\begin{tabular}{|c|c|c|c|}
\hline Behavioural risk factors & $\begin{array}{l}\text { Number of participants who } \\
\text { declared not using condom } \mathbf{N} \text { (\%) }\end{array}$ & $\begin{array}{l}\text { Last occasional intercourse } \\
\text { without using condom } \mathbf{N} \text { (\%) }\end{array}$ & $\begin{array}{l}\text { Median number of sexual partners } \\
\text { during the last } 12 \text { months } \mathbf{N}(\%)\end{array}$ \\
\hline \multicolumn{4}{|l|}{ Age group } \\
\hline $15-24$ & $56(60.2)$ & $54(58.1)$ & 1.0 \\
\hline $25-34$ & $50(61.7)$ & $49(60.5)$ & 1.0 \\
\hline $35-45$ & $26(74.3)$ & $23(65.7)$ & 1.0 \\
\hline $45+$ & $22(84.6)$ & $14(53.8)$ & 1.0 \\
\hline \multicolumn{4}{|l|}{ Gender } \\
\hline Male & $96(6 \mid .9)$ & $98(63.2)$ & 2.0 \\
\hline Female & $58(72.5)$ & $42(52.5)$ & 1.0 \\
\hline DIFF $[95 \% \mathrm{Cl}]$ Female/Male & $10.6(-2.0 ; 23.0)$ & - $10.7(-24.0 ; 3.0)$ & NA \\
\hline \multicolumn{4}{|l|}{ Education } \\
\hline None & $73(76.8)$ & $54(56.8)$ & 1.0 \\
\hline Some & 81 (5I.9) & $86(61.4)$ & 2.0 \\
\hline DIFF [95\% Cl] None/Some & $24.9(13.0 ; 36.8)$ & $-4.6(-17 ; 8.0)$ & NA \\
\hline \multicolumn{4}{|l|}{ Marital status } \\
\hline Single & $36(55.4)$ & $34(52.3)$ & 2.0 \\
\hline Other & 118 (69.4) & $106(62.4)$ & 1.0 \\
\hline DIFF [95\%Cl] Other/Single & $14(.07 ; 28)$ & $10.1(-4 ; 24)$ & NA \\
\hline
\end{tabular}

DIFF $[95 \% \mathrm{Cl}]=$ Difference in Proportion with $95 \%$ confidence interval

NA: Not Applicable

Table 4: Crude* and adjusted** odds ratio (OR) estimates with their $95 \%$ Confidence Interval (95\% CI) of the effect of perceived efficacy of condom, barriers to condom use, vulnerability and severity on the lack of condom use for 235 participants in a HIVIAIDS interview, Toffo county, Benin (June-July 2002).

\begin{tabular}{lll}
\hline Variables & Crude OR' $(95 \% \mathrm{Cl})$ & Adjusted OR $^{2}(95 \% \mathrm{Cl})$ \\
\hline No perceived risk to HIV infection & $6.9(0.9-52.5)$ & $\mathrm{NA}^{3}$ \\
AIDS not perceived as a deadly disease & $2.5(0.3-19.7)$ & $\mathrm{NA}^{3}$ \\
Perceived incomplete protection using condoms & $11.5(3.8-34.7)$ & $9.8(3.2-30.0)$ \\
Reporting any problem using condom & $5.4(2.1-13.7)$ & $3.6(1.3-9.9)$
\end{tabular}

2 LL Chi-square: 32.2 P-value $<0.0001$

Score Chi-square: 32.2 P-value $<0.000$ I

C-statistic $=0.81$

'Crude OR: calculated from a univariate logistic regression

${ }^{2}$ Adjusted OR: Calculated from a multivariate logistic regression including Perceived incomplete rotection using condoms and reporting any problem using condom.

${ }^{3} \mathrm{NA}$ : Not Applicable because these variables did not have an important effect on the use of condom.

infection $(\mathrm{OR}=6.9,95 \% \mathrm{CI}=0.9-52.5)$ was not strictly statistically significant since most interviewees felt vulnerable, reducing the power of detecting a significant difference. This variable was also a weak confounder for the effect of perceiving the condom as ineffective. Not perceiving HIV/AIDS as a deadly disease $(\mathrm{OR}=2.5,95 \% \mathrm{CI}=$ 0.3 - 19.7) was not associated with the lack of use of condoms.

\section{Discussion}

This study was the first ever to use the Health Belief Model (HBM) to assess cultural behaviour in rural Benin towards condom use and HIV/AIDS. The HBM was reported to be one of the most widely used behavioural frameworks for more than five decades but has been criticized for its inability to efficiently predict people's behaviour [14]. There is general agreement that the components of HBM should include self-efficacy and cues to action, and that susceptibility and severity should be conditional on action or inaction $[13,14]$. The lack of generally accepted model construct also makes comparisons difficult across studies. An effort was made in this study to address these concerns by clearly defining the model's construction. 
Our results showed there is a high awareness on AIDS in general and that women knew more about the modes of transmission of HIV/AIDS and its impacts than men. Conversely, women were more likely to feel that they could identify HIV-infected individuals from their symptoms. In addition, females were less likely to declare using condom in general even though a higher proportion declared having used condom during the last occasional sexual intercourse. This finding is disturbing and could be explained by the difference in perception of the question "do you use condoms?" It is difficult to judge what the true answer is but it is likely that rare events are better reported, and thus women may be more prone to recall the use of condom than men during occasional intercourse given that they declared on average fewer sexual partners. It is also possible that among women who do use condom, they will use it more regularly than men.

Our measure of perceived vulnerability might not be sensitive enough to capture differences in perceived risks. In fact, all women and most men felt they were at risk of acquiring the infection, yet only a small proportion were using condoms. Another explanation may be that perceived risk is not a driving force in behavioural change in this subset of the population. This is an illustration of the complexity of modeling human behaviour and can thus make a case for further cultural-specific HIV-behavioural research. When only considering the percentage of condom use by gender, females appear to be at a higher risk of acquiring HIV even though they appeared to know more about transmission routes and prevention methods. This might be due to the well established difficulty facing women in negotiating the terms of sexual intercourse. In fact, gender inequality is associated with poverty, condom with distrust and sexual economic exchange is not perceived as prostitution [19]. All these factors make women vulnerable to acquire HIV infection, and therefore it is important to consider empowerment of women, gender inequality and poverty as key strategies of HIV/AIDS prevention programmes.

Despite a relatively acceptable knowledge of modes of transmission and prevention methods, only a few of participants declared using condoms, which is an indication that a relatively good knowledge about HIV/AIDS, even though necessary, may not be a key factor in behavioural change in fighting HIV epidemic in the study population. These findings also indicate that programmes which aim only at increasing awareness and knowledge may not succeed.

Using the HBM to analyze the determinants of behavioural change in our study population, we can conclude that there is a high-perceived vulnerability and perceived severity, and yet this does not encourage condom use. An important proportion of participants do not believe in the efficacy of condoms and there are barriers to the use of condoms.

Our results are comparable to that found in a similar study in the USA [20] and in a review of published studies using HBM [14] where perceived barriers were found to be the single most powerful predictors of the HBM. Our findings are also consistent with results of studies conducted in Kenya [21] and in Ghana [22], in which perceived barriers were found as being the strongest predictors of condom use. However, these results can not be generalized across settings For example, in a study conducted among American university students, the HBM did not significantly explain condom use but rather condom use was associated with sexual practices [23]. Perceived benefit of avoidance of pregnancy was found as one of the strongest predictors of consistent condom use in New York female adolescents [24] and in Zimbabwe social support was found to be the most consistent factor associated with sexual risk reduction [25]. These observed differences in the strongest(s) predictor(s) of the HBM can be noticed through several other works [26-30]. Hence, it appears important to conduct operational behavioural researches in each local setting to identify factors that influence condom use.

One limitation of our study was that for ethical reasons, subjects less than 15 years old were excluded even though some may have already been sexually active. Also, there was a potential selection bias by not having equal number of interviewers by gender, which resulted in an over-sampling of males. Our results would be biased if the reason for poor recruitment of women was linked to their behaviours, which is not likely to be the case. There were three males interviewers for one female (difficulties in recruiting female educated social worker in the area), and interviewer/participants must be from same gender. For the purposes of the analysis we assumed that reported knowledge and behavioural risk factors are independent. Finally there is no evidence for the validity or reliability for the original WHO questionnaire, however its use allows for comparability of results across settings.

\section{Conclusions}

Condom use, in our study population, depends on its perceived quality and perceived efficacy. There is an indication that behavioral communication change strategies based on increasing perceived risk or vulnerability of the population or based on fear factor by increasing perceived severity of HIV/AIDS are less likely to be deterrent towards condom use and require more researches. HIV outreach programs must target more barriers of condoms use. Condom outreach programmes should be defined at community level and must be defined in association with the 
Table 5: Survey items, HIVIAIDS and condom use survey, Toffo county, Benin (June - July 2002).

\begin{tabular}{ll}
\hline SURVEY ITEMS RESPONSE CATEGORIES & RSO
\end{tabular}

\section{General knowledge on HIVIAIDS}

I. Have you ever heard about HIVIAIDS

2. In your knowledge how severe is HIVIAIDS

3. How could someone get infected by HIV?

4. Who you think are at risk of getting HIV?

5. In your knowledge, what are the prevention methods of getting HIV?

6. How could you recognize a HIV-infected person?

\section{Beliefs on HIVIAIDS}

7. Do you believe HIV really exists?

8. Do you think you are at risk of getting HIV?

9. If no to 8) why?

10. Where you believe HIV originates from?

II. Do you think one can completely cure from HIVIAIDS?

12. If yes to II) how?

13. How would you rate the protective effect provided by condoms?

14. Does your religion believe HIV exists?

15. What is the position of your religion towards condom use?

\section{Behaviors and attitudes}

16. Would you mind taking a HIV screening test if you were asked?

17. Do you use condoms?

18. If No or No answer to 17) why?

19. How often do you use condoms?

20. Did you use condom during the last occasional intercourse?

21 . Do you encounter any problem using condoms?

22. If yes to 21 ) what type of problems

23. Numbers of sexual partners during the last 12 months

\section{Socio demographic characteristics}

24. Age

25. Sex

26. Marital status

27. Education (Ability to read)

28. Occupation

29. Religion

30. Place (please give the name of your village)
Yes/No

Deadly, don't know, imaginary, other

At least 2, one or no correct answer(s),

Everyone/specific groups/Don't know

Abstinence, Fidelity, Condom, Other, Don't know

Could not, Cachexia, Other symptoms, Don't know

Yes/No/Don't know

Yes/No/Don't know

Fidelity/Condom use/Other/Don't know

God/Bewitchment/Other/Don't know

Yes/No/Don't know

Medicine/Herbs/Prayers/Other/Don't know

Complete/Incomplete/Useless/Don't know

Yes/No/Don't know

Favorable/Unfavorable/Indifferent/Don't know

Yes / No / Don't know

Yes / No / No answer

Don't like / Only God save / Other

Always / Sometimes / Never

Yes / No

Yes / No

Less lubrificated / Less pleasure / break easily / Other

Full years

Male / Female

Married monogamous / Married polygamous/ Single / Divorced /

Widowed / Separated

Fluent / With difficulty / Not able to read at all

Student / Farmer /

Christianity / Islam / Animist / Other

Village name

Adapted from the World Health Organization / Global AIDS Program's questionnaire

community, using problem-solving techniques and selecting the most relevant targets, based on their importance and changeability [13]. Data from this study could be useful for the design and planning of health intervention programmes, resource allocation and evaluation of condom outreach activities in Benin.

\section{Competing interests}

The author(s) declare that they have no competing interests.

\section{Authors' contributions}

SHH conceived of the study, designed the protocol, carried out and supervised the field work and data collection, performed and interpreted the statistical analysis and wrote the manuscript. HC participated in analysis and interpretation of the data, and in the writing of the manuscript. NJH contributed in earlier analysis of the data and reviewed the manuscript. All authors read and approved the final manuscript.

\section{Acknowledgments}

The authors thank all the individuals who accepted to participate in this study. We also thank Dr Medegan-Fagla Valentine for her contribution during the design stage of the questionnaire, Drs Meda Nicolas, and Hassan Jacques for the review of an earlier version of the manuscript. We acknowledge the United States Agency for International Development (USAID), which provides funding through the ATLAS Fellowship. 


\section{References}

I. World Bank Group, les partenariats contre le SIDA: I'expérience de l'Afrique australe dans le changement du comportement sexuel. [http://www.worldbank.org/afr/findings/french/ffind84.htm].

2. INSAE, ORC MACRO: Enquête Démographique et de Santé au Bénin. Cotonou 2002.

3. ONUSIDA: Rapport sur l'épidémie mondiale de VIH/SIDA. Genève 2000.

4. Centre de Coopération Internationale en Santé et Développement (CCISD) [http://www.ccisd.org/fra/index3a.html]

5. Programme National de Lutte contre le Sida: Rapports Annuels. Cotonou 2001.

6. UNB, INE, CEFORP: Enquête sur les connaissances, attitudes et pratiques relatives au SIDA, à la diarrhée, au paludisme et à la planification familiale. Cotonou 2000.

7. Fagla-Medegan V: Prévalence de I'infection a VIH et autres infections sexuellement transmissibles et études des facteurs de risque associés chez les routiers au Bénin. Cotonou 2001.

8. Ministère de la Santé: Annuaires Statistiques. Cotonou 2000.

9. ADJOVI CV: Surveillance de l'infection par le VIH/SIDA/IST au Bénin. Cotonou 200I.

10. Brownson RC, Remington PL, Davis JR: Chronic disease epidemiology and control. American Public Health Association 2000.

II. Brookmeyer R, Gail MH: AIDS Epidemiology. A Quantitative Approach. New-York: Oxford University Press; 1994.

12. XIe International Conference on AIDS. The status and trends of the global HIVIAIDS pandemic, final report [http:www.fhi.org/en/aids/aidscap/aidspubs/special/statustrends/van pan.html]

13. Coreil J, Bryant CA, Henderson JN: Social and Behavioral Foundations of Public Health. CA, USA: Sage Publications, Inc; 2001.

14. Glanz K, Rimer BK, Lewis FM: Health behavior and health education, theory research and practice. NJ, USA: John Wiley \& Sons, Inc; 2002.

15. Resource Center for Adolescent Pregnancy Prevention (ReCAPP): Theories and Approaches: Health Belief Model. [http://
[ www.etr.org/recapp/theories/hbm].

16. EPI INFO [http://www.cdc.gov/epiinfo]

17. SPSS I I.0 [http://www.sc.edu./ardc/docs/spssinst | |5.htm]

18. SAS 8.1 [http://www.sas.com]

19. Parker RG, Easton D, Klein $\mathrm{CH}$ : Structural barriers and facilitators in HIV prevention: a review of international research. AIDS 2000, I 4(I):22-32.

20. Mahoney CA, Thombs DL, Ford OJ: Health belief and self-efficacy models: Their utility in explaining college students condom use. AIDS Educ Prev 1995, 7(I):32-49.

21. Mattson M: Towards a reconceptualization of communication cues to action in the health belief model: HIV test counseling. Commun Monogr 1999, 66(3):240-265.

22. Adih WK, Alexander CS: Determinants of condom use to prevent HIV infection among youth in Ghana. J Adolesc Health 1999, 24(I):63-72.

23. Lollis CM, Johnson $\mathrm{EH}$, Antoni $\mathrm{MH}$ : The efficacy of health belief model for predicting condom usage and risky sexual practices in University students. AIDS Educ Prev 1997, 9(6):55 I-63.

24. Laraque D, McLean DE, Brown-Peterside $P$, Ashton D, Diamond $B$ : Predictors of reported condom use in central Harlem youth as conceptualized by the health belief model. J Adolesc Health | 997, 2 I(5):318-27.

25. Wilson D, Lavelle S: Psychological predictors of intended condom use among Zimbabwean adolescents. Health Educ Res 1992, 7(I):55-68.

26. Wolk JE, Koopman C: Factors associated with condom use in Kenya: a test of the health belief model. AIDS Educ Prev 200I, I 3(6):495-508.

27. Sowell RL: Factors influencing intent to get pregnant in HIVinfected women living in the Southern USA. AIDS Care 2002, |4(2): $181-191$.

28. Roye CF, Seals BA: Qualitative assessment of condom use decisions by female adolescents who use hormonal contraception. J Assoc Nurses AIDS Care 200I, I 2(6):78-87.

29. Gielen AC, Faden RR, O'Campo P, Caisson R, Watkinson L: Women's protective sexual behaviors: a test of the health belief model. AIDS Educ Prev 1994, 6( I): I- I I.
30. Ford K, Norris AE: Factors related to condom use with casual partners among urban African-American and Hispanic males. AIDS Educ Prev 1995, 7(6):494-503.

\section{Pre-publication history}

The pre-publication history for this paper can be accessed here:

http://www.biomedcentral.com/1471-2458/5/8/prepub
Publish with Biomed Central and every scientist can read your work free of charge

"BioMed Central will be the most significant development for disseminating the results of biomedical research in our lifetime. "

Sir Paul Nurse, Cancer Research UK

Your research papers will be:

- available free of charge to the entire biomedical community

- peer reviewed and published immediately upon acceptance

- cited in PubMed and archived on PubMed Central

- yours - you keep the copyright

Submit your manuscript here:

http://www.biomedcentral.com/info/publishing_adv.asp
BiolMedcentral 